\title{
Erratum to: Prevalence and related factors of common mental disorders during pregnancy in Japan: a cross-sectional study
}

Kentaro Usuda ${ }^{1,2,3}$, Daisuke Nishi ${ }^{1,2,3^{*}}$, Miyuki Makino ${ }^{1,5}$, Hisateru Tachimori ${ }^{3}$, Yutaka Matsuoka ${ }^{4}$, Yo Sano $^{1}$, Takako Konishi $^{6}$ and Tadashi Takeshima ${ }^{7}$

\section{Erratum}

After publication of the original article [1], the authors noticed there was an error to the values for "Generalized anxiety disorder", "Obsessive-compulsive disorder" and "PTSD (Post traumatic stress disorder)" listed underneath the "\% (95\% CI)" column. The correct version of Table 2, is included in this erratum.

\begin{abstract}
Author details
'Toda Chuo Women's Hospital, 2-26-3 Kamitoda, Toda, Saitama 335-0022, Japan. ${ }^{2}$ Tokyo Medical University, 6-7-1 Nishishinjuku, Shinjuku-ku, Tokyo 160-0023, Japan. ${ }^{3}$ Department of Mental Health Policy and Evaluation, National Institute of Mental Health, National Center of Neurology and Psychiatry, 4-1-1 Ogawa-Higashi, Kodaira, Tokyo 187-8553, Japan. ${ }^{4}$ Center for Public Health Sciences, National Cancer Center, 5-1-1 Tsukizi, Chuo-ku, Tokyo 104-0045, Japan. ${ }^{5}$ National Center for Cognitive Behavior Therapy and Research, National Center of Neurology and Psychiatry, 4-1-1 Ogawa-Higashi, Kodaira, Tokyo 187-8553, Japan. ${ }^{6}$ Musashino University, 3-3-3 Ariake, Koto-ku, Tokyo 135-8181, Japan. ${ }^{7}$ Health and Social Welfare Bureau, Kawasaki City Office, 3-16-1 Ida, Nakahara-ku, Kawasaki, Kanagawa 211-0035, Japan.
\end{abstract}

Received: 23 August 2016 Accepted: 23 August 2016

Published online: 05 September 2016

\section{Reference}

1. Usuda K, et al. Prevalence and related factors of common mental disorders during pregnancy in Japan: a cross-sectional study. BioPsychoSoc Med. 2016;10:17. doi:10.1186/s13030-016-0069-1.

\footnotetext{
* Correspondence: d-nishi@umin.ac.jp

${ }^{1}$ Toda Chuo Women's Hospital, 2-26-3 Kamitoda, Toda, Saitama 335-0022, Japan

${ }^{2}$ Tokyo Medical University, 6-7-1 Nishishinjuku, Shinjuku-ku, Tokyo 160-0023, Japan

Full list of author information is available at the end of the article
}

Submit your next manuscript to BioMed Central and we will help you at every step:

- We accept pre-submission inquiries

- Our selector tool helps you to find the most relevant journal

- We provide round the clock customer support

- Convenient online submission

- Thorough peer review

- Inclusion in PubMed and all major indexing services

- Maximum visibility for your research

Submit your manuscript at www.biomedcentral.com/submit (c) 2016 The Author(s). Open Access This article is distributed under the terms of the Creative Commons Attribution 4.0 International License (http://creativecommons.org/licenses/by/4.0/), which permits unrestricted use, distribution, and reproduction in any medium, provided you give appropriate credit to the original author(s) and the source, provide a link to the Creative Commons license, and indicate if changes were made. The Creative Commons Public Domain Dedication waiver (http://creativecommons.org/publicdomain/zero/1.0/) applies to the data made available in this article, unless otherwise stated. 
Table 2 Prevalence of psychiatric diagnosis at gestational age 12 weeks to 24 weeks in a local maternity hospital (Total $=177)$

\begin{tabular}{lll}
\hline Diagnosis & Number & $\%(95 \% \mathrm{Cl})$ \\
\hline Mood disorders & 2 & $1.1(0.00-0.04)$ \\
$\quad$ Major depression & 0 & $0.0(0.00-0.00)$ \\
Dysthymia & 0 & $0.0(0.00-0.00)$ \\
Manic episode & & \\
Anxiety disorders & 2 & $1.1(0.00-0.04)$ \\
Panic disorder & 7 & $3.9(0.02-0.08)$ \\
Agoraphobia & 2 & $1.1(0.00-0.04)$ \\
Social anxiety disorder & 0 & $0.0(0.00-0.00)$ \\
$\quad$ Generalized anxiety disorder & 3 & $1.7(0.01-0.05)$ \\
Obsessive-compulsive disorder & 1 & $0.6(0.00-0.03)$ \\
PTSD (Post traumatic stress disorder) & & \\
Substance use disorders & & $1.1(0.00-0.04)$ \\
Alcohol dependence & 2 & $0.0(0.00-0.00)$ \\
Alcohol abuse & 0 & $0.0(0.00-0.00)$ \\
Drug dependence & 0 & $0.0(0.00-0.00)$ \\
Drug abuse & 0 & $0.0(0.00-0.00)$ \\
Eating disorders & & $0.0(0.00-0.00)$ \\
Anorexia nervosa & $0.031)$ \\
Bulimia nervosa & 0.11 & \\
At least one diagnosis & &
\end{tabular}

